\title{
Improvement of Atypical Nocturnal Vocalization Accompanied with Obstructive Sleep Apnea after Continuous Positive Airway Pressure Treatment
}

\author{
Young-Soo Kim ${ }^{1,2}$, Jung-Hwan $\mathrm{Oh}^{3}$ \\ ${ }^{1}$ Department of Neurology, Gyeongsang National University Hospital, Jinju, \\ ${ }^{2}$ Department of Neurology and Institute of Health Science, Gyeongsang National University College of Medicine, Jinju, \\ ${ }^{3}$ Department of Neurology, Jeju National University College/School of Medicine, Jeju, Korea
}

\author{
지속형 양압기 치료로 호전을 보인 폐쇄수면무호흡과 동반된 비전형 야간발성 \\ 김 영 수 ${ }^{1,2}$, 오 정 환 ${ }^{3}$ \\ 경상대학교병원 신경과, ${ }^{1}$ 경상대학교 의과대학 신경과학교실 및 건강과학연구원, ${ }^{2}$ 제주대학교 의과대학/의학전문대학원 신경과학교실 ${ }^{3}$
}

Received November 7, 2019

Revised November 30, 2019

Accepted December 2, 2019

Address for correspondence Jung-Hwan Oh, MD

Department of Neurology, Jeju National University College/ School of Medicine,

15 Aran 13-gil, Jeju 63241, Korea

Tel: $+82-64-717-1620$

Fax: +82-64-717-1620

E-mail: oh.junghwan77@gmail.com
Catathrenia is a rare chronic disorder characterized by expiratory groaning during sleep. Neither the origin of this sound nor the pathophysiology underpinning catathrenia is understood. Although the International Classification of Sleep Disorders, 2nd edition (ICSD-2) included catathrenia among "other parasomnias," catathrenia was classified as a respiratory disorder in the 2014 ICSD-3. Several case series of this condition have been reported, but the clinical descriptions of the sound duration and intensity, usual stage of sleep at which it occurs, and treatment response differ across cases. The possibility that catathrenia is not a single disorder has also been considered. When typical catathrenia symptoms are present, but overnight polysomnography findings do not meet the typical diagnostic criteria, a diagnosis of atypical nocturnal vocalization is given. We report a case of atypical nocturnal vocalization mimicking catathrenia that accompanied obstructive sleep apnea and improved after continuous positive airway pressure therapy.

J Sleep Med 2019;16(2):116-119

Key Words: Respiratory sounds, Sleep apnea syndromes, Parasomnias. 야간발성(nocturnal vocalization)은 수면 중에 발생하는 비정상적인 소리를 통칭하는 포괄적인 개념이다. 신음소리 (groaning), 잠꼬대(sleep talking) 등 수면 동안 나타나는 여 러 가지 소리가 여기에 속하는데, 아직까지 이에 대한 구체 적인 정의나 분류 체계는 정립된 바가 없다. ${ }^{1}$ 야간발성 중 대 표적인 질환인 catathrenia는 특발성(idiopathic) 만성질환으 로 잠을 자면서 특징적인 패턴의 신음소리를 내는 것이 주 증상이다. ${ }^{2}$ 수면다원검사에서 깊게 숨을 들이쉰 후 내쉬는 동 안 신음소리가 반복적으로 발생될 때 진단할 수 있다. ${ }^{3}$ 발병 기전이 밝혀지지 않았지만 호흡리듬장애(respiratory dys-

This is an Open Access article distributed under the terms of the Creative Commons Attribution Non-Commercial License (https://creativecommons.org/licenses/by-nc/4.0) which permits unrestricted non-commercial use, distribution, and reproduction in any medium, provided the original work is properly cited. rhythmia)가 발생에 관여하고 일부 환자에서 경미한 산소포 화도 저하(oxygen desaturation)를 보이는 특징을 근거로 지 속형 양압기(continuous positive airway pressure, CPAP) 치 료가 시도되었다. ${ }^{4} \mathrm{CPAP}$ 치료에 대한 반응은 보고마다 차이 는 있으나 전반적으로 효과가 있다고 알려져 있다. ${ }^{5}$ 1983년 De Roeck 등이 처음으로 catathrenia를 보고한 후, ${ }^{6}$ 많은 증 례가 보고되었으나, 그중에는 국제수면장애분류 2판(International Classification of Sleep Disorders, 2nd edition, ICSD-2) 진단 기준에 부합하지 않는 경우도 있었다. 2,7 저자 들은 수면 중 지속되는 신음소리를 주소로 내원한 환자에서 수면다원검사 결과 폐쇄수면무호흡과 동반되며, catathrenia 의 전형적인 소견을 보이지 않은 비전형 야간발성을 $\mathrm{CPAP}$ 으로 치료한 예를 경험하여 보고한다. 


\section{증 례}

55세 여자 환자가 수면 중 신음소리를 주소로 내원하였다. 수면 중 신음소리를 낸다는 것을 본인은 인지하지 못했고 언 제부터 이 증상이 시작되었는지 알지 못했다. 남편을 통해 처음 알게 되었고, 이 소리로 인해 남편뿐 아니라 여행 시 다 른 동침자의 수면에 방해가 될까 봐 잠들기가 두렵다고 하였 다. 환자는 기관지 천식 등의 내과적 질환이나 정신과적 질 환은 없었고, 가족력에도 특이한 소견은 없었다. 현재 복용 하고 있는 약물은 없었고 술과 담배는 하지 않았다. 신체 진 찰에서 폐 청진상 호흡음은 정상이었고, 변형 Mallampati 등 급은 2단계, Friedman 병기 분류에 따른 편도 크기는 1 등급 이었으며, 체질량지수는 $27.4 \mathrm{~kg} / \mathrm{m}^{2}$ 였다. 수면 관련 척도인 엡워스 졸음척도, 스탠포드 졸음척도 및 피츠버그 수면의 질 평가척도는 각각 0 점, 1 점 및 12 점이었다. 첫 번째 수면다원 검사(COMET PSG, Twin 4.5.2 Software, Grass Technologies, Warwick, RI, USA) 결과 총 269분 수면 시간에 수면 효 율은 65.9\%였다. 1단계 수면이 19.3\%, 2단계 수면 68.5\%, 렘수 면은 $11.7 \%$ 로 나타났고, 서파수면은 $0.6 \%$ 로 감소되는 구조를 보였다. 무호흡-저호흡지수(apnea-hypopnea index, AHI)는 $13.8 / \mathrm{h}$ 이었다. 야간발성(nocturnal vocalization)이 수면 중에 관찰되었는데(Fig. 1), 2초 미만의 짧은 기간 동안 고음역대 의 단조로운 음색의 신음소리가 날숨 시기에 반복적으로 나 타났고, 소리가 들렸을 때 코골이 센서에서 파형의 변화는
관찰되지 않았다. 이러한 소리는 렘수면과 서파수면에서 관 찰되지 않았고, 1단계 수면에서 70회(44\%), 2단계 수면에서 89 회(89\%)를 보여 총 159 회(35.4/h)가 기록되었다. 각성과 동반되는 횟수는 2 회였고, 폐쇄무호흡증과 동반된 경우는 1 회였다. 별다른 치료 없이 지내던 환자는 수면 중 신음소리가 더 심해져서 4년만에 다시 외래를 방문하였다. 다시 시행한 수 면다원검사 결과 총 수면 시간은 339.3분, 수면 효율은 $88.1 \%$ 였 으며, AHI는 $15.7 / \mathrm{h}$ 이었다. 1단계, 2단계, 서파수면 및 렘수면 은 각각 $35.2 \%, 46.4 \%, 4.1 \%$ 및 $14.3 \%$ 의 비율을 보였다. 야간 발성은 1단계 수면에서 535회(58\%), 2단계 수면에서 216회 (23\%), 3단계 수면에서는 관찰되지 않았고, 렘수면에서 175회 (19\%)로 총 횟수는 926회(22.6/h)였고, 이전보다 증가된 양 상이었다. 또한 각성과 동반되는 횟수는 29회, 폐쇄수면무호 흡과 동반된 경우는 15 회로 이 또한 이전보다 증가된 소견이 었다. 한 달 후 $\mathrm{CPAP}$ 적정을 위해 수면다원검사를 다시 시 행하였고 $7 \mathrm{cmH}_{2} \mathrm{O}$ 의 압력에서 야간발성이 소실되었고, $\mathrm{AHI}$ 도 $2.3 / \mathrm{h}$ 로 감소되어, $7 \mathrm{cmH}_{2} \mathrm{O}$ 압력을 유지하기로 했다. $\mathrm{CPAP}$ 사용 2개월 후 남편을 통해 환자의 수면 중 신음소리가 없어졌음을 확인했고, 1 개월간 $\mathrm{CPAP}$ 치료 결과 4시간 이상 $\mathrm{CPAP}$ 착용률은 $77 \%$ 였고, $\mathrm{AHI}$ 는 $3.1 / \mathrm{h}$ 으로 기록되었다.

본 연구는 제주대학교병원 기관생명윤리심의위원회 $(\mathrm{In}-$ stitutional Review Board, IRB)의 심의를 거쳐 승인을 받았 다(JNUH IRB No. 2019-11-005).

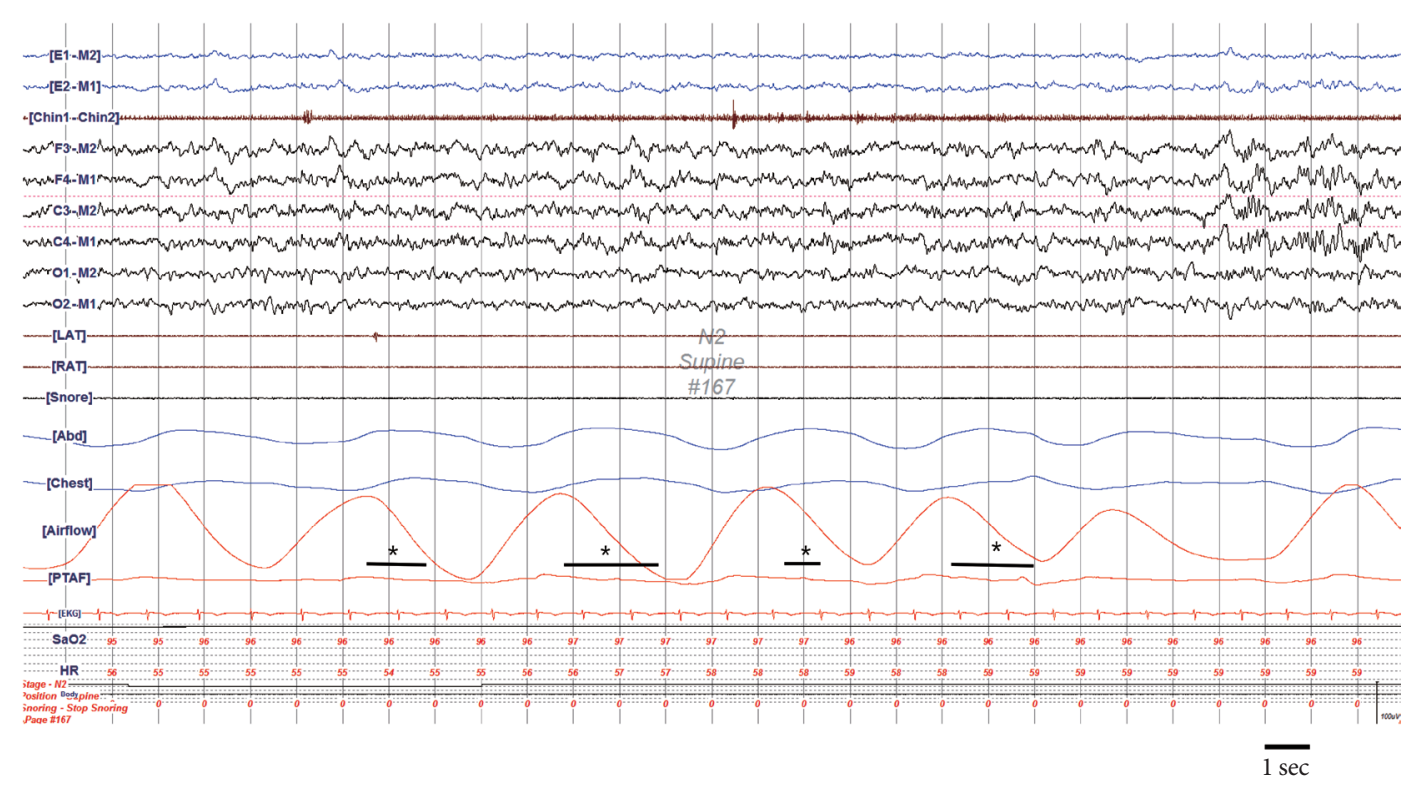

Figure 1. This 30 -second epoch polysomnogram demonstrates periodic groaning $\left(^{*}\right)$ during N2 stage sleep. It is a high-pitched monotonous sound lasting for approximately 1 or 2 seconds during the expiration phase. Top 2 channels: electrooculogram, Chin 1-Chin 2: chin electromyogram, six channels consisting of F3-M2, F4-M1, C3-M2, C4-M1, O1-M2, O2-M1: electroencephalogram, LAT: electromyogram on left anterior tibialis muscle, RAT: electromyogram on right anterior tibialis muscle, Snore: snore sensor, Abd: abdomen respiratory effort channel, Chest: chest respiratory effort channel, Airflow: oro-nasal thermal sensor, PTAF: pressure transducer airflow, EKG: electrocardiography, SaO2: oxyhemoglobin saturation by pulse oximetry, HR: heart rate. 


\section{고 찰}

수면 관련 발성 질환 중 가장 대표적인 유형인 catathrenia 는 수면 중 일정한 음색의 불규칙한 신음을 특징으로 하는 드문 질환이다. ${ }^{2} 1983$ 년 De Roeck 등이 렘수면 단계에서 신 음소리를 내는 증례로 처음 보고하였다. ${ }^{6}$ 2001년 Pevernagie 등도 렘수면에서 긴 날숨 기간 동안 발생하는 발성 (vocalization)을 보인 10명 환자를 보고하였다. ${ }^{8}$ 소리가 주 증상이기는 하지만 코골이와 달리 숨을 내쉬는 동안 소리가 발생하고 산 소포화도 감소가 일반적으로 동반되지 않아 사건수면(parasomnia)의 형태로 판단했고, 약물치료와 CPAP 치료를 시도 했으나 충분히 조절되지 않는다고 기술하였다.8 'Catathrenia' 라는 명칭은 2001년 Vetrugno 등이 수면 중 발생하는 신음소 리 환자 4명을 보고하면서 처음 사용하였다. ${ }^{2}$ 이 환자들의 증 상은 이전 보고와는 달리 비렘수면 시기에도 발생한다고 기술 하였다. 2005년 Oldani 등은 '야간신음소리(nocturnal groaning)'라는 진단명으로 12 명 증례를 보고하였는데 수면다원검 사 결과 소리를 동반하지 않은 깊은 들숨 후 신음소리를 동반 한 날숨이 2 20초가량 지속되는 전형적인 패턴을 기술하였 다. ${ }^{9}$ 이 보고를 바탕으로 ICSD-2에서 catathrenia의 진단 기 준을 제시하였다. ${ }^{3}$ 이후 catathrenia가 의심되는 야간발성 증 례가 많이 보고되었으나, ICSD-2 기준에 합당하지 않거나 치료에 대한 반응, 소리가 주로 나타나는 수면 단계 등이 일 치하지 않는 환자들이 일부 보고되면서 임상적 특징에 대한 논쟁이 시작되었다.,7 2012년 Abbasi 등은 수면다원검사를 통 해 catathrenia를 진단받은 10 명 환자의 수면다원검사 결과와 증상의 음향과 영상 자료를 분석하여 발표했다. ${ }^{1} 10$ 명의 환자 에서 총 1,026 회의 야간발성이 기록되었고, 이를 ICSD-2 정의 에 합당한 2초 이상의 지속시간을 보인 경우 전형 catathrenia (typical catathrenia events)로 분류하고 그보다 짧을 경우 비전형 야간발성(atypical nocturnal vocalization events) 으로 나누어 분류하였다. 전형 catathrenia의 발현 횟수는 전 체 $5 \%(52 / 1,026)$ 였고, 10 명 중 5 명에서 확인되었다. 나머지 95\%(974/1,026)는 ICSD-2의 정의에 부합하지 않았지만 catathrenia로 진단했다고 밝혔다. 이들은 ICSD-2 기준에 합당하지 않는 95\%의 비전형 야간발성을 확장된(extended) catathrenia 진단에 포함시킬 것인지 추가적인 연구가 필요하 다고 주장하였다. ${ }^{1}$ 2015년 Iriarte 등은 지금까지 catathrenia로 보고된 증례를 소리의 특징, 환자의 인적 자료(demographics), 주로 나타나는 수면 단계, 동반 증상, CPAP 치료에 대 한 반응 등을 비교한 후 두 가지 유형으로 나누었다..$^{5}$ 첫 번 째 유형은 소리의 기간이 길고, 렘수면에서 주로 관찰되며, 중추성 무호흡과 연관이 있고, CPAP 치료에 반응이 없는 특
징을 가지고 있었다. 두 번째 유형은 소리의 기간이 1 3초로 짧고, 렘수면과 비렘수면 모두 관찰되며, 호흡질환의 동반이 뚜렷하지 않거나 폐쇄수면무호흡이 동반된 경우가 많고, $\mathrm{CPAP}$ 치료에 반응이 좋은 특징을 가지고 있었다. 결론적으 로 지금까지 보고된 catathrenia는 두 가지 유형(아형, variant) 으로 나눌 수 있고, 하나의 질환으로 완전히 정의되지 않았으 며, 메커니즘과 본질에 대한 중요한 질문이 아직 해결되지 않 았다고 정리하였다. ${ }^{5}$ 본 증례의 경우 임상적으로 catathrenia 가 의심되었으나 수면다원검사 결과 ICSD-2 기준에 합당한 전형적인 catathrenia 패턴의 호흡과 다르고, 소리를 내는 기간 또한 2초 미만인 경우가 대부분이었다(Fig. 1) 따라서 Abbasi 등의 제안에 따르면 비전형 야간발성에 합당하고, Iriarte 등이 제시한 catathrenia의 두 가지 아형 중 두 번째 유형에 해당한 다. 1.5 본 증례의 이러한 소리는 앞서 언급한 대로 코골이 센서 에서 감지되지 않았고, 들숨이 아닌 날숨에 주로 발생하여 코 골이나 협착음(stridor)과도 구별할 수 있었다.

Catathrenia는 병인이 알려져 있지 않아 치료 방법도 명확 하지 않지만, 이전 보고에서 안정제(sedatives) 투여나 CPAP 이 시도되었다. 28,9 한 연구에서 10 명의 catathrenia 환자 중 8 명에게 clonazepam과 같은 약물을 사용하여 50\%에서 호전 되었음을 보고했고, $\mathrm{CPAP}$ 치료를 시도한 2명 중 1명은 전혀 호전이 없었다고 기술하였다. ${ }^{8}$ 폐쇄수면무호흡을 진단하는 과정에서 catathrenia를 확인한 경우나 catathrenia 환자에게 서 폐쇄수면무호흡이 동반된 경우 CPAP을 적용하면 폐쇄 수면무호흡 외 catathrenia 증상도 호전된 예들이 보고되었 다. 5.7 이 경우 코골이나 수면무호흡의 동반 여부와 상관없이 catathrenia 환자에게 $\mathrm{CPAP}$ 의 적용은 효과적인 치료라고 주 장하였다. 또한 본 증례와 유사한 비전형 야간발성 환자 10명 중 6명에서 수면호흡질환(sleep-disordered breathing)이 동 반되었고, 4명에게 $\mathrm{CPAP}$ 을 적용한 결과 $\mathrm{CPAP}$ 을 적용한 4명 모두 비전형 야간발성이 감소했다. ${ }^{1}$

ICSD-2에서 사건수면으로 분류된 catathrenia는 이후 불규 칙호흡(respiratory dysrhythmia)과 동반된 느린호흡(bradypnea), 특징적인 소리가 주 증상임이 알려져 국제수면장애분 류 3판(ICSD-3)에서는 수면호흡질환에 포함되었다. ${ }^{10}$ 본 증 례의 경우 두 번째 수면다원검사에서 첫 번째 검사보다 야간 발성의 횟수 및 $\mathrm{AHI}$ 가 증가되었고, 폐쇄수면무호흡과 연관된 야간발성도 증가하였다. $\mathrm{CPAP}$ 으로 야간발성과 함께 $\mathrm{AHI}$ 도 호전을 보여, 이러한 비전형 야간발성도 전형적인 catathrenia 와 동일하게 수면 관련 호흡질환으로 분류되는 것이 합당할 것으로 생각된다.

2005년 이후 catathrenia에 대한 많은 연구가 보고되었으 나 여러 연구에서 제시하는 임상 증상과 소리의 분석 결과 일 
치하지 않는 측면이 많았다. ${ }^{1,5}$ 또한 catathrenia와 유사한 증 상을 보이는 일부 환자 중에는 진단 기준에 합당하지 않는 경 우 다른 분류 체계가 적용되어야 한다는 의견도 제시되었다. ${ }^{7}$ 본 증례는 야간발성을 주 증상으로 내원하여 catathrenia를 의 심하고 수면다원검사를 진행하였으나 전형적인 catathrenia 의 기준에 합당하지 않았다. 따라서 catathrenia의 아형으로 판 단되는 비전형 야간발성으로 진단하였다. 야간발성과 함께 폐쇄수면무호흡이 동반되어 CPAP 치료를 적용하였고 무호 흡과 함께 야간발성도 호전되었다.

Catathrenia는 하나의 질환으로 설명할 수 없고 추가적인 유형이 있거나 다른 질환이 포함되었을 가능성이 높다. ${ }^{5}$ 따라 서 catathrenia를 포함하여 수면 관련 발성질환을 이해하기 위해서는 병태생리에 관한 체계적인 연구가 필요할 것이다.

\section{Acknowledgments}

None.

\section{Conflicts of Interest}

The authors have no potential conflicts of interest to disclose.

\section{ORCID iDs}

Young-Soo Kim https://orcid.org/0000-0003-1040-372X

Jung-Hwan Oh https://orcid.org/0000-0003-3997-3267

\section{Author Contributions}

Conceptualization: Young-Soo Kim, Jung-Hwan Oh. Data curation: Jung-Hwan Oh. Formal analysis: Jung-Hwan Oh. Investigation: YoungSoo Kim. Methodology: Young-Soo Kim, Jung-Hwan Oh. Supervision:
Jung-Hwan Oh. Writing_original draft: Young-Soo Kim. Writing-review \& editing: Jung-Hwan Oh.

\section{REFERENCES}

1. Abbasi AA, Morgenthaler TI, Slocumb NL, Tippmann-Peikert M, Olson EJ, Ramar K. Nocturnal moaning and groaning-catathrenia or nocturnal vocalizations. Sleep Breath 2012;16:367-373.

2. Vetrugno R, Provini F, Plazzi G, Vignatelli L, Lugaresi E, Montagna P. Catathrenia (nocturnal groaning): a new type of parasomnia. Neurology 2001;56:681-683.

3. Duchna HW. [Sleep-related breathing disorders--a second edition of the International Classification of Sleep Disorders (ICSD-2) of the American Academy of Sleep Medicine (AASM)]. Pneumologie 2006;60:568575 .

4. Songu M, Yilmaz H, Yuceturk AV, Gunhan K, Ince A, Bayturan O. Effect of CPAP therapy on catathrenia and OSA: a case report and review of the literature. Sleep Breath 2008;12:401-405.

5. Iriarte J, Campo A, Alegre M, Fernández S, Urrestarazu E. Catathrenia: respiratory disorder or parasomnia? Sleep Med 2015;16:827-830.

6. De Roeck J, van Bockstaele M, De Potter WP. The effect of pentylenetetrazol on the levels of dopamine-beta-hydroxylase in the cerebrospinal fluid of rabbits: a dose-dependent relationship. Neurosci Lett 1983;35: 65-70.

7. Guilleminault C, Davis K, Huynh NT. Prospective randomized study of patients with insomnia and mild sleep disordered breathing. Sleep 2008;31:1527-1533.

8. Pevernagie DA, Boon PA, Mariman AN, Verhaeghen DB, Pauwels RA. Vocalization during episodes of prolonged expiration: a parasomnia related to REM sleep. Sleep Med 2001;2:19-30.

9. Oldani A, Manconi M, Zucconi M, Castronovo V, Ferini-Strambi L. 'Nocturnal groaning': just a sound or parasomnia? J Sleep Res 2005;14: 305-310.

10. Li Q, Wang Q. [Sleep related breathing disorders in international classification of sleep disorders-3]. Zhonghua Jie He Не Hu Xi Za Zhi 2014;37: 883-884. 